\title{
Ophiostoma species (Ophiostomatales, Ascomycota), including two new taxa on eucalypts in Australia
}

\author{
G. Kamgan Nkuekam ${ }^{1}$, Z. Wilhelm de Beer ${ }^{1}$, Michael J. Wingfield ${ }^{1}$, Caroline Mohammed ${ }^{2}$, \\ Angus J. Carnegie ${ }^{3}$, Geoff S. Pegg ${ }^{4}$ and Jolanda Roux ${ }^{1}$
}

(1) Department of Microbiology and Plant Pathology, DST/NRF Centre of Excellence in Tree Health Biotechnology, Forestry and Agricultural Biotechnology Institute (FABI), University of Pretoria, Pretoria, South Africa.

(2) School of Agricultural Science, University of Tasmania, GPO Box 252-54, Hobart, Tas. 7001, Australia.

(3) Forest Science Centre, Industry \& Investment NSW, PO Box 100, Beecroft, NSW 2119, Australia.

(4) Agric-Science Queensland, Ecosciences Precinct, 41 Boggo Road, Dutton Park, Brisbane, Qld 4102, Australia.

\section{Jolanda Roux}

Email: jolanda.roux@fabi.up.ac.za

\section{Abstract}

The genus Ophiostoma accommodates ascomycetes in the order Ophiostomatales, some of which are important pathogens of trees. Although these fungi are well known in the northern hemisphere, very little is known regarding their occurrence or importance in Australia. The aim of the present study was to collect Ophiostoma spp. infecting wounds on Eucalyptus spp. in Australia, where most of these trees are native. Collections were made in three states of Australia and the isolates were identified using morphological and multigene-sequence comparisons. Of the 76 isolates collected, two previously unknown species of Ophiostoma were found and these are described here as $O$. tasmaniense sp. nov. and O. undulatum sp. nov. In addition, O. quercus (Georgev.) Nannf. and $O$. tsotsi Grobbelaar, Z.W.de Beer \& M.J.Wingf. are reported for the first time from eucalypts in Australia and the distribution of Pesotum australiae Kamgan Nkuekam, Jacobs \& Wingfield is expanded to include eucalypts in Tasmania. In pathogenicity tests, very small lesions were observed in both the bark and xylem of E. grandis (Hill) Maiden trees, suggesting that none of the collected species is a pathogen of Eucalyptus spp.

\section{Introduction}

The Ophiostomatales are ascomycetes that include Ophiostoma H. \& P. Sydow with Pesotum J.L. Crane \& Schokn. and Sporothrix Hektoen \& C.F. Perkins anamorphs, Ceratocystiopsis H.P. Upadhyay \& W.B. Kendr with Hyalorhinocladiella H.P. Upadhyay \& W.B. Kendr anamorphs and Grosmannia Goid. with Leptographium Lagerb. \& Melin anamorphs (Upadhyay 1981; Zipfel et al. 2006). These genera are commonly referred to as ophiostomatoid fungi and they produce fruiting structures with similar morphologies adapted to insect dispersal (Wingfield et al. 1993). Sexual forms of these fungi are mostly ascomata with long necks, exuding sticky spores at their apices that attach easily to the bodies of passing insects, which transport them to new substrates (Upadhyay 1981; Wingfield et al. 1993; Jacobs and Wingfield 2001). Asexual forms are erect conidiophores with sticky spores at their apices (Hyalorhinocladiella, Pesotum and Leptographium) or dry spores 
(Sporothrix) that can be wind-dispersed (Crane and Schoknecht 1973; Malloch and Blackwell 1993; Jacobs and Wingfield 2001).

Ophiostoma H. \& P. Sydow species with their Pesotum and Sporothrix anamorphs include important pathogens of trees such as O. ulmi (Buisman) Nannf. and O. novo-ulmi Brasier, responsible for two Dutch elm disease pandemics that have devastated elm trees in Europe and the United States of America (Sinclair and Lyon 2005). Numerous other Ophiostoma spp. are agents of sapstain, causing discoloration of timber, thus reducing its commercial value (Seifert 1993). A well known example is O. quercus (Georgev.) Nannf., causing sapstain on E. grandis (Hill) Maiden trees in South Africa (De Beer et al. 2003). However, blue stain is much better known where it occurs on conifers (Seifert 1993).

Ophiostomatoid fungi require wounds to infect trees and they are commonly vectored by arthropods. Most Ophiostoma spp. depend on bark beetles or weevils for their dispersal and typically have a mutualistic relationship with these insects (Mathiesen-Käärik 1953; Whitney 1982; Paine et al. 1997; Kirisits 2004). In this regard, they also have a close association with phoretic mites associated with these insects (Bridges and Moser 1986; Levieux et al. 1989; Malloch and Blackwell 1993; Moser 1997). This association with timber-infesting insects makes the ophiostomatoid fungi especially well adapted for accidental introduction into new environments.

The eucalypts include more than 700 tree species distributed in three genera, Eucalyptus L'Her., Corymbia K.D. Hill \& L.A.S. Johnson and Angophora Cav. (Hill and Johnson 1995). Almost all eucalypts are endemic to Australia, with only a few species that are restricted to some islands in southern Asia (Potts and Pederick 2000). In their native range, Eucalyptus spp. constitute $\sim 78 \%$ of forests, whereas more than $85 \%$ of hardwood plantations comprise Eucalyptus spp. (Anonymous 2009). In the rest of the world, eucalypts have been planted for more than 200 years and, presently, numerous species are grown in plantations, covering more than 20 million hectares in more than 60 countries (Iglesias-Trabado and Wilstermann 2008). In this regard, they represent a significant element of the economies of countries where they provide fuel, paper pulp and construction timber.

At least 10 fungal species residing in the Ophiostomatales are known from trees in Australia, including the human pathogen Sporothrix schenkii Hektoen \& C.F. Perkins (Conias and Wilson 1998), and two species isolated from mouldy hay, Ophiostoma stenoceras (Robak) Nannf. and $O$. nigrocarpum (R.W. Davidson) de Hoog (O'Reilly and Altman 2006). Almost all the other species have been isolated from stained and/or bark beetle-infested non-native Pinus spp. These include Ophiostoma ips (Rumb.) Nannf. (Stone and Simpson 1987, 1989, 1991), Ceratocystiopsis minuta (Siem.) Upadh. \& Kendrick (Stone and Simpson 1989), Grosmannia huntii (R.C. Rob.-Jeffr.) Zipfel, Z.W. de Beer \& M.J. Wingf. (Jacobs et al. 1998), O. quercus, O. floccosum Mathiesen, Pesotum fragrans (Mathiesen) Okada \& Seifert (Harrington et al. 2001), an unidentified species of Leptographium (Vaartaja 1967) and Pesotum (reported as Graphilbum) (Stone and Simpson 1991). To the best of our knowledge, the only member of the Ophiostomatales reported from a host tree native to Australia is Pesotum australiae Kamgan Nkuekam, Jacobs \& M.J.Wingf. that occurs on wounds on native Acacia mearnsii de Wild (as 'P. australi'; Kamgan Nkuekam et al. 2008a). On the basis of the recent descriptions of numerous previously undescribed species of Ophiostoma from hardwoods elsewhere in the world, it is highly likely that numerous species await discovery in Australia and especially on eucalypts that dominate the natural landscape. Knowledge of these species on eucalypts in their native range would be valuable in elucidating the origin and movement of wood-inhabiting pathogens in this genus.

This investigation represents a collaborative effort between researchers from Universities and Forestry Departments in Australia and South Africa. The aim was to increase available knowledge pertaining to the Ophiostomatales occurring in Australia. Wounds on eucalypt trees in the eastern 
part of Australia were thus inspected for the presence of these fungi. All isolates were identified using a combination of morphological and DNA-sequence data and their potential pathogenicity to these trees was tested in greenhouse inoculation studies.

\section{Materials and methods}

\section{Collection of samples}

Surveys for Ophiostomatales infecting Eucalyptus and Corymbia spp. in Australia were conducted between March and April in 2008. Samples were collected from stumps as well as from wounds made by stem-boring insects (e.g. Phoracantha spp.). Sampling was undertaken in the states of Tasmania, New South Wales and the southern part of Queensland. In Tasmania, areas sampled included numerous localities near Burnie, Tarraleah and Geevestown. In New South Wales (NSW), commercial plantations and native eucalypt forests between Sydney and up to the border with Queensland were visited. Some key areas sampled in NSW included Pine Creek State Forest, Wattagan State Forest, Wedding Bells State Forest, Crab-Tree plantation, Ingalba State Forest and other localities around these main areas. In the state of Queensland, samples were collected from Eucalyptus trees grown close to south-eastern Queensland.

After determining the presence of ophiostomatalean fruiting structures (mycelium, ascomata, synemata) with $\mathrm{a} \times 20$ magnification lens, pieces of wood were cut from trees and placed in separate brown paper bags for each tree sampled. All the samples in bags were placed in larger plastic bags to prevent desiccation and to promote sporulation, and were transported to the laboratory.

Isolations and purification of fungi from wood samples were carried out as described by Kamgan Nkuekam et al. (2008a, 2008b). Ten additional isolates collected in Australia during previous surveys (2005) were obtained from the culture collection (CMW) of the Forestry and Agricultural Biotechnology Institute (FABI, www.fabinet.up.ac.za) at the University of Pretoria. These isolates originated from felled Eucalyptus grandis logs infested by cerambycid beetles near Brisbane. All isolates used in the study were deposited in the culture collection (CMW) of the Tree Pathology Cooperative Program (TPCP), South Africa, and representative cultures have also been deposited with the Centraalbureau voor Schimmelcultures (CBS), Utrecht, Netherlands. Dried specimens of representative isolates were deposited in the National Collection of Fungi (PREM), Pretoria, South Africa. Representative isolates of species closely related to the Australian species isolated in the present study, and for which insufficient DNA-sequence data were available from GenBank, were obtained for reference purposes from CMW (Table 1). These included those for O. borealis G. Kamgan Nkuekam, H. Solheim \& Z.W. de Beer, O. denticiliatum Linnakoski, Z.W. de Beer \& M.J. Wingf., O. karelicum Linnakoski, Z.W. de Beer \& M.J. Wingf. and P. australiae.

\section{Culture characteristics and morphology}

Isolates resembling fungi in the Ophiostomatales were grouped into morphotypes on the basis of features of their cultures on oatmeal agar media (OMA: $30 \mathrm{~g}$ oats, $20 \mathrm{~g}$ Biolab agar and $1000 \mathrm{~mL}$ deionised water). Single drops of conidia, ascospores or small pieces of mycelium were transferred from pure cultures to OMA to promote sporulation for morphological comparisons. Cultures were incubated at $25^{\circ} \mathrm{C}$ until sporulation and then grouped into morphotypes on the basis of colour (Rayner 1970) and macro-morphology. Fruiting structures (ascomata and ascospores; synnemata and conidia) of selected isolates representing each of the morphotypes were mounted in $80 \%$ lactic acid on microscope slides and studied under a Zeiss Axiocam light microscope (Zeiss, MünchenHallbergmoos, Germany). Fifty measurements of all characteristic morphological features were made for isolates chosen as the types of new species and 10 measurements were made for additional 
isolates. The means were then calculated for relevant morphological structures. Measurements were noted as (minimum-) mean minus s.d. - mean plus s.d. (-maximum).

Table 1. List of Ophiostoma isolates and their morphogroups collected during the surveys in Australia and sequenced in the study. Reference species for which TEF was sequenced for comparative studies are listed below the morphogroups. $\mathrm{T}=$ ex-type isolate.

\begin{tabular}{|c|c|c|c|c|c|c|c|c|}
\hline \multirow[t]{2}{*}{ Morphogroup } & \multirow[t]{2}{*}{ ID } & \multirow[t]{2}{*}{ Host } & \multirow[t]{2}{*}{ CMW } & \multicolumn{3}{|c|}{ Accession number } & \multirow[t]{2}{*}{ Collector } & \multirow[t]{2}{*}{ Country } \\
\hline & & & & ITS & BT & TEF & & \\
\hline \multirow[t]{15}{*}{$\mathrm{A} 1$} & O. quercus & $\begin{array}{l}\text { Corymbia } \\
\text { variegata }\end{array}$ & 29552 & NA & NA & NA & G. Kamgan Nkuekam & Australia \\
\hline & & Eucalyptus dunii & ${ }^{B} 29279$ & NA & NA & $\mathrm{NA}$ & G. Kamgan Nkuekam & Australia \\
\hline & & E. agglomerata & 29277 & NA & NA & NA & G. Kamgan Nkuekam & Australia \\
\hline & & E. grandis & 29299 & GU797206 & GU797194 & GU797224 & G. Kamgan Nkuekam & Australia \\
\hline & & E. nitens & 29091 & GU797207 & GU797192 & NA & G. Kamgan Nkuekam & Australia \\
\hline & & & ${ }^{B} 29096$ & NA & NA & NA & G. Kamgan Nkuekam & Australia \\
\hline & & & 29103 & GU797203 & GU797193 & GU797221 & G. Kamgan Nkuekam & Australia \\
\hline & & E. globulus & 29117 & NA & NA & NA & G. Kamgan Nkuekam & Australia \\
\hline & & & 29118 & GU797204 & GU797198 & GU797222 & G. Kamgan Nkuekam & Australia \\
\hline & & & 29356 & NA & NA & NA & G. Kamgan Nkuekam & Australia \\
\hline & & & 24755 & NA & NA & $\mathrm{NA}$ & M.J. Wingfield & Australia \\
\hline & & & 24750 & GU797205 & GU797195 & $\mathrm{NA}$ & M.J. Wingfield & Australia \\
\hline & & & 24743 & NA & NA & NA & M.J. Wingfield & Australia \\
\hline & & & 24745 & GU797208 & GU797197 & NA & M.J. Wingfield & Australia \\
\hline & & & 24758 & GU797202 & GU797196 & NA & M.J. Wingfield & Australia \\
\hline \multirow[t]{6}{*}{$\mathrm{A} 2$} & O. tasmaniense & E. globulus & $\mathrm{A}, \mathrm{B}, \mathrm{C}_{2} 9115$ & GU797209 & GU797190 & GU797225 & G. Kamgan Nkuekam & Australia \\
\hline & & & ${ }^{A, C} C_{29116}$ & GU797212 & GU797191 & GU797226 & G. Kamgan Nkuekam & Australia \\
\hline & & E. nitens & $\mathrm{C}_{29086}$ & NA & NA & NA & G. Kamgan Nkuekam & Australia \\
\hline & & & $\mathrm{T}, \mathrm{A}, \mathrm{B}, \mathrm{C} 29088$ & GU797211 & GU797188 & GU797223 & G. Kamgan Nkuekam & Australia \\
\hline & & & $\mathrm{C}_{29099}$ & GU797210 & GU797189 & GU797220 & G. Kamgan Nkuekam & Australia \\
\hline & & E. saligna & 29272 & NA & NA & NA & G. Kamgan Nkuekam & Australia \\
\hline A3 & P. australiae & E. nitens & $\mathrm{C}_{29101}$ & GU797213 & GU797184 & GU797232 & G. Kamgan Nkuekam & Australia \\
\hline \multirow[t]{9}{*}{ A4 } & O. tsotsi & E. grandis & 29293 & GU797216 & GU797199 & GU797229 & G. Kamgan Nkuekam & Australia \\
\hline & & E. pilularis & 29294 & GU797214 & GU797200 & GU797228 & G. Kamgan Nkuekam & Australia \\
\hline & & & 29432 & NA & NA & NA & G. Kamgan Nkuekam & Australia \\
\hline & & & 29433 & NA & • & ' & G. Kamgan Nkuekam & Australia \\
\hline & & & ${ }^{B} 29539$ & NA & · & · & G. Kamgan Nkuekam & Australia \\
\hline & & & 29540 & GU797215 & GU797201 & GU797227 & G. Kamgan Nkuekam & Australia \\
\hline & & & ${ }^{\mathrm{B}} 29541$ & NA & NA & NA & G. Kamgan Nkuekam & Australia \\
\hline & & & 29543 & NA & NA & NA & G. Kamgan Nkuekam & Australia \\
\hline & & & 29548 & NA & NA & $\mathrm{NA}$ & G. Kamgan Nkuekam & Australia \\
\hline \multirow[t]{5}{*}{ B } & O. undulatum & E. grandis & $c_{19392}$ & NA & NA & NA & M.J. Wingfield & Australia \\
\hline & & & A,C 19394 & GU797219 & GU797185 & GU797235 & M.J. Wingfield & Australia \\
\hline & & & $\mathrm{T}, \mathrm{A}, \mathrm{B}, \mathrm{C} 19396$ & GU797218 & GU797186 & GU797233 & M.J. Wingfield & Australia \\
\hline & & & A,B,C 19397 & GU797217 & GU797187 & GU797234 & M.J. Wingfield & Australia \\
\hline & & & 19402 & NA & NA & NA & M.J. Wingfield & Australia \\
\hline \multirow{8}{*}{$\begin{array}{l}\text { Reference } \\
\text { strains }\end{array}$} & O. borealis & Tilia cordata & 17860 & EF408594 & GQ249311 & GU930823 & T. Kirisits & Austria \\
\hline & & Betula pubescens & ${ }^{\mathrm{T}} 18966$ & EF408593 & GQ249317 & GU930822 & G. Kamgan Nkuekam & Norway \\
\hline & O. denticiliatum & $\begin{array}{l}\text { Scolytus ratzeburgi } \\
\text { from Betula sp. }\end{array}$ & 'T29493 & FJ804490 & FJ804502 & GU930818 & R. Linnakoski & Norway \\
\hline & & · & ${ }^{\mathrm{T}} 29494$ & FJ804491 & FJ804503 & GU930819 & R. Linnakoski & Norway \\
\hline & O. karelicum & · & ${ }^{\mathrm{T}} 23099$ & EU443762 & EU443773 & GU930821 & R. Linnakoski & Russia \\
\hline & & • & 23101 & EU443763 & EU443774 & GU930820 & R. Linnakoski & Finland \\
\hline & P. australiae & Acacia mearnsii & 6589 & EF408602 & EF408605 & GU797231 & M.J. Wingfield & Australia \\
\hline & & • & T6606 & EF408603 & EF408606 & GU797230 & M.J. Wingfield & Australia \\
\hline
\end{tabular}

\footnotetext{
A Isolate used for growth studies.

${ }^{\mathrm{B}}$ Isolate used in pathogenicity trials.

Isolate used for mating compatibility trials.

NA, not available.
}

Scanning electron microscopy (SEM) was used to observe fruiting bodies (conidia, conidiophores) of the asexual states of the fungi. For this purpose, specimens were prepared as described by Grobbelaar et al. (2010). The specimens were critical point-dried (Bio-Rad E3000, Watford, England), then mounted and coated with gold in a sputter coater (Emitech K550X, Ashford, England) and examined with a JEOL JSM-840 scanning electron microscope (JEOL, Tokyo, Japan). 


\section{Growth in culture}

Three isolates of each undescribed species (Table 1) identified in the present study were used for growth studies in culture. This was carried out on malt extract agar (MEA) at seven different temperatures $\left(5-35^{\circ} \mathrm{C}\right)$, following the technique described by Kamgan Nkuekam et al. (2008a).

\section{DNA-sequence comparisons}

Representative isolates of each morphological group of fungi were selected for DNA-sequence comparisons. Single spore drops collected from the apices of ascomata or conidiophores in pure cultures were grown on 2\% MEA for 7-10 days. Mycelium was scraped from the surfaces of the actively growing cultures and then transferred into 1.5-mL Eppendorf tubes with a sterile hypodermic needle. DNA was extracted using PrepMan Ultra Sample Preparation Reagent (Applied Biosystems, Foster City, CA, USA), following the manufacturer's instructions.

The internal transcribed spacer regions (ITS1, ITS4) and 5.8S gene of the rRNA operon were amplified on an Eppendorf Mastercycler (Merck, Hamburg, Germany) with primers ITS1 and ITS4 (White et al. 1990). Part of the $\beta$-tubulin gene (BT) and the transcription elongation factor- $1 \alpha$ gene (TEF) were also amplified with the primers T10 (O'Donnell and Cigelnik 1997) and Bt2b (Glass and Donaldson 1995), and EF1F and EF2R (Jacobs et al. 2004), respectively.

The PCR reaction mixtures and thermal cycling conditions were the same as those described previously (Kamgan Nkuekam et al. 2008a, 2008b). An aliquot of $5 \mu \mathrm{L}$ of the PCR products were stained with GelRed ${ }^{\mathrm{TM}}$ nucleic acid gel stain (Biotium, Hayward, CA, USA), separated on a 1\% agarose gel and visualised under UV light. PCR products were purified using Sephadex G-50 Gel (Sigma-Aldrich, Steinheim, Germany), following the manufacturer's instructions. Subsequently, the concentrations of the purified PCR products were determined using a Nanodrop ND-1000 spectrophotometer (Nanodrop Technologies, Rockland, DE, USA). Sequencing reactions were performed using the Big Dye cycle sequencing kit with Amplitaq DNA polymerase, FS (PerkinElmer, Warrington, UK), following the manufacturer's protocols on an ABI PRISM 3100 Genetic Analyzer (Applied Biosystems). Sequencing PCRs were prepared as described by Kamgan Nkuekam et al. (2008b) and both DNA strands were sequenced for each gene region. Sequences for both strands of each isolate were examined visually and consensus sequences were assembled using Sequence Navigator (Applied Biosystems Division, Perkin-Elmer, Foster City, CA, USA).

A preliminary identity for the isolates was obtained by performing a standard nucleotide BLAST against the GenBank database (http://www.ncbi.nlm.nih.gov). Datasets comprising sequences obtained in the present study, as well as reference sequences of related species obtained from GenBank, were compiled in MEGA 4.0.2 (Tamura et al. 2007). Sequences were then aligned automatically by using the online version of MAFFT 6 (Katoh et al. 2002). Data for the three gene regions sequenced were analysed separately from each other, and three types of analyses were carried out for each dataset. First, PAUP 4.0b10 (Sinauer Associates, Sunderland, MA, USA) was used to construct phylogenetic trees from the distance matrices by pairwise alignment of the sequences, using the maximum-parsimony (MP) method. Confidence levels of the phylogenies were estimated with 1000 bootstrap replicates. Additionally, Bayesian analyses were performed with MrBayes 3.1 (Ronquist and Heuelsenbeck 2003), based on Markov Chain Monte Carlo (MCMC) methods. Appropriate substitution models were determined using the Akaike information criterion (AIC) in MrModeltest 2.2 (http://www.abc.se/ nylander/). The models applied to the ITS, $\mathrm{BT}$ and TEF datasets were $\mathrm{GTR}+\mathrm{I}+\mathrm{G}, \mathrm{SYM}+\mathrm{G}$ and $\mathrm{GTR}+\mathrm{G}$, respectively. Four simultaneous MCMCs were run for 1000000 generations and trees were sampled every 100th generation. The burn-in procedure in MrBayes 3.1 was used to discard the first trees that formed before the point of convergence, and the posterior probabilities in the majority-rule consensus trees were calculated by 
MCMC sampling in MrBayes 3.1, using the best-fit model of evolution mentioned above. Last, maximum-likelihood (ML) analyses were conducted online by using PhyML 3.0 (Guindon and Gascuel 2003). The AIC was used in Modeltest 3.7 (Posada and Crandall 1998) to select appropriate substitution models for the three datasets. For ITS, the selected model was GTR $+\mathrm{I}+\mathrm{G}$ (gamma shape parameter $=0.6097$; Pinvar $=0.6101)$, for the BT it was $\mathrm{TVM}+\mathrm{G}$ (gamma shape parameter $=0.1904$, Pinvar $=0)$ and GTR $+G($ gamma shape parameter $=1.0065$, Pinvar $=0)$ for the TEF dataset.

\section{Pathogenicity tests}

Pathogenicity tests were conducted in a quarantine greenhouse, using Eucalyptus grandis clone TAG5. This clone was selected because it has been shown to be susceptible to a range of fungal pathogens in previous studies. Two strains each (Table 1), for four of the fungal species identified in the present study, were used in the inoculation experiment. Ten trees, approximately 2 -years old $(\sim 1$ $\mathrm{cm}$ diameter), grown in plastic bags, were inoculated with each test strain and two other trees of the same age were inoculated with a sterile agar disc to serve as controls. Inoculations were carried out at an average temperature of $25^{\circ} \mathrm{C}$ and natural day/night lighting conditions of $\sim 13 \mathrm{~h}$ daylight and $11 \mathrm{~h}$ darkness, using the same technique as described before by Kamgan Nkuekam et al. (2008b). Six weeks (42 days) after inoculation, the lengths of lesions on the bark surface and in the xylem of each tree were measured. Re-isolations were made from the lesions to meet the requirements of Koch's postulates. All data were processed using the statistical software package SAS ${ }^{\circledR}$ V8 (SAS Inc., Cary, NC, US) running under VM/CMS on the main-frame computer at the University of Pretoria, where lesion lengths were analysed using GENMOD with a POISSON distribution and a link function of log.

\section{Mating compatibility}

To obtain sexual states for isolates collected in the present study that did not produce teleomorphs on wood or in culture (Table 1), single conidial isolates were paired in all possible combinations on water agar (20 $\mathrm{g} \mathrm{L}^{-1}$ agar, Biolab, Midrand, South Africa and $1000 \mathrm{~mL}$ sterile deionised water) supplemented with sterile Eucalyptus chips (Kamgan Nkuekam et al. 2008a; Grobbelaar et al. 2010). Petri dishes were incubated at $25^{\circ} \mathrm{C}$ for 1 month and monitored weekly for the presence of ascomata producing ascospores.

In a separate experiment, strains of Pesotum australiae (CMW6606, CMW6589, CMW6588, CMW6590) collected from wounds of $A$. mearnsii trees, and identified in a previous study (Kamgan Nkuekam et al. 2008a), were crossed in the same manner with a strain (CMW29101) collected from a wound on a Eucalyptus tree in the present study. These latter pairings were conducted in an attempt to stimulate production of ascomata for $P$. australiae, which have not previously been seen for this species.

\section{Results}

\section{Collection of samples}

In total, 66 isolates resembling species in the Ophiostomatales were collected from 200 eucalypt trees sampled during the surveys in New South Wales, Queensland and Tasmania. Samples from which fungi were isolated included wounds on two eucalypt genera, Eucalyptus and Corymbia, including eight different species. These tree species were E. nitens Deane \& Maiden, E. globulus Labill, E. pilularis Sm., E. saligna Sm., E. agglomerata Maiden, E. dunnii Maiden, E. grandis and C. variegata (F.Muell.) K.D. Hill \& L.A.S. Johnson. Apart from some discoloration of the wood around the wounds, there were no other symptoms suggestive of a disease problem. 


\section{Culture characteristics and morphology}

Isolates could be assigned to two morphological groups on the basis of colony morphology and the type of fruiting bodies produced on either MEA or OMA. Isolates collected in 2008 all shared similar culture morphology (Table 1, Group A), with no sexual states observed, and resembled species of Pesotum. Colonies of these isolates sporulated best on OMA. They produced only synnemata, with creamy to white spore drops. No ascomata were produced in culture. Isolates collected in Queensland, near Brisbane in 2005, could be grouped in a second morphological group (Table 1, Group B), which was characterised by slower growth than that of isolates in Group A. Ascomata with long necks, exuding creamy ascospore drops, were often produced in culture. These isolates produced white mycelial mats with undulating colony surfaces and Sporothrix anamorphs in culture.

\section{DNA-sequence comparisons}

Representative isolates from different hosts and geographic locations were selected for DNA sequencing (Table 1). All of these isolates generated fragments of $\sim 600 \mathrm{bp}$ for the ITS, $400 \mathrm{bp}$ for the BT and $800 \mathrm{bp}$ for the TEF gene regions. BLAST searches in the GenBank database showed that all isolates belonged in the genus Ophiostoma and its related anamorph genus, Pesotum. Alignments of ITS sequence data for isolates from Australia with those of related Ophiostoma spp. from GenBank, resulted in a total of 589 characters including gaps, with 489 constant characters, 20 parsimony-uninformative characters and 80 parsimony-informative characters. The aligned BT dataset consisted of a total of 241 characters including gaps, with 146 constant characters, nine parsimony-uninformative characters and 86 parsimony-informative characters. The TEF dataset consisted of a total of 552 characters including gaps, with 92 constant characters, 21 parsimonyuninformative characters and 439 parsimony-informative characters. For reference species, TEF sequences were not available in GenBank and they were consequently generated in the present study (Table 1).

Phylogenetic analyses using MP generated 144 trees for the ITS, 273 trees for the BT, and 1117 trees for the TEF datasets. The consistency index (CI) values for the three datasets were 0.778 , 0.634 and 0.679 , respectively, whereas the retention index (RI) values were $0.918,0.914$ and 0.925 , respectively. For each dataset, a 50\% majority-rule tree was obtained from Bayesian analyses and a bootstrap tree was also obtained from a MP as well as from ML analyses. For each dataset, a ML tree is presented (Figs 1-3), indicating at the relevant nodes, MP bootstrap values, Bayesian posterior probabilities, and ML bootstrap values, respectively.

Isolates representing both morphological groups could not be resolved fully in the phylogenetic analyses using the ITS gene region (Fig. 1) and were scattered within the tree and intermingled with species such as $O$. quercus, O. tsotsi Grobbelaar, Z.W. de Beer \& M.J. Wingf., O. denticiliatum and $P$. australiae. However, within this complex, isolates representing Group B formed a distinct clade, which was most closely related to O. quercus, with $100 \%$ support in all three analyses.

In the BT tree (Fig. 2), Group A isolates separated into four lineages. The first set of isolates grouped with strains of $O$. quercus (A1). The second set of isolates formed a well supported clade (A2), distinct from, but most closely related to O. quercus. A single isolate grouped with the two Pesotum australiae isolates (A3), whereas the fourth set of isolates grouped in a well supported lineage with strains of $O$. tsotsi (A4). As was the case for the ITS region, isolates in Group B formed a well supported, distinct clade, although this time most closely related to P. australiae. 
. quercus AY466622 Azerbaijan

O. quercus AY466626 France

O. quercus AF198237 Germany

O. quercus AY466611 Azerbaljan

O. quercus AY573251 Belgium

O. quercus DQ539522 Spain

O. quorcus AF198238 UK

O. quorcus GQ249323 Norway

CMW29118 Australia

CMW24745 Australia

CMW29356 Australia

CMW24750 Australia

CMW24743 Australia

O. quercus AF493241 South Africa

O. quercus EF408563 South Africa

O. quorcus EU443764 Finland

O. quercus EF408579 Sweden

- O. quercus FJ804488 Norway

CMW24755 Australia

O. quercus AF493252 New zealand

CMW29091 Australia

CMW24758 Australia

O. quercus AF081132 Canada

O. quercus AF493236 Japan

CMW29279 Australia

O. quorcus FJ434957 China

CMW29117 Australia

$100 / 100 / 100$

CMW19394 Australia

CMW19396 Australia T

CMW19392 Australia

CMW19397 Australia

CMW19402 Australia

\section{CMW29096 Australia}

CMW29103 Australia

CMW29299 Australia

O. quorcus AF493243 Brazil

B: O. undulatum sp. nov.

O. quercus AY328520 Chile

O. quercus EF408590 Austria

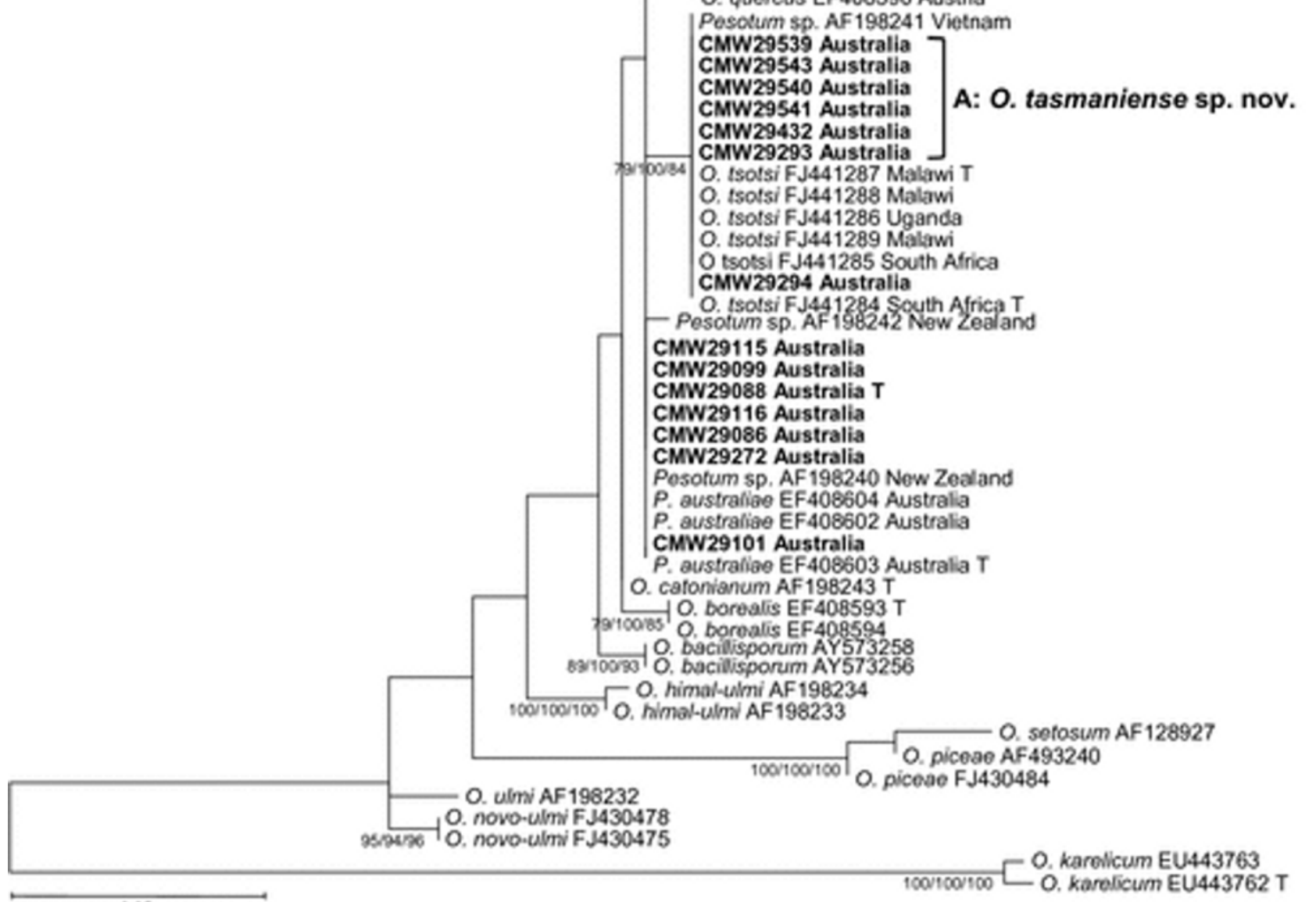

0.05

Figure 1. Phylogenetic tree produced from a maximum likelihood analysis of the internal transcribed spacer region (ITS) sequence data, showing the placement of Ophiostoma and Pesotum isolates from eucalypt trees in Australia among known species of Ophiostoma. Isolates sequenced in the study are in bold type font. Maximum-parsimony (MP) bootstrap values, Bayesian posterior 
probabilities and maximum-likelihood (ML) bootstrap values, respectively, are indicated at each relevant node. $\mathrm{T}=$ ex-type isolates.

Analyses of the TEF dataset gave results similar to those obtained with the BT dataset (Fig. 3). These data confirmed with good support the distinction of especially Clades A2 and B2 from, respectively, $O$. tsotsi and $P$. australiae. Furthermore, TEF data of $O$. denticiliatum, $P$. australiae, $O$. karelicum and $O$. borealis isolates separated all four of these species into lineages that are distinct from other species in the complex.

\section{Mating compatibility}

The Pesotum isolates (Table 1, Goup A2) that did not produce ascomata in culture and that were paired in all possible combinations, produced sexual fruiting bodies typical of the genus Ophiostoma on Eucalyptus chips. The crosses between the reference $P$. australiae isolates (Table 1) from a previous study, and the single isolate (CMW29101) identified as $P$. australiae on the basis of DNA sequences from the present study, did not produce ascomata.

\section{Taxonomy}

On the basis of morphological examinations and multigene sequence phylogenies, two Ophiostoma spp. from Australia emerged as distinct and previously undescribed species. The following descriptions are provided for them.

Ophiostoma undulatum Kamgan-Nkuek, M.J. Wingf. \& Jol.Roux, sp. nov. (Fig. 4)

Etymology: The name refers to the undulating mycelium of colonies on growth media.

Coloniae albae vel bubalinae in MEA in 10 diebus in $25^{\circ} \mathrm{C}$ ad $16 \mathrm{~mm}$ crescentes. Mycelium tegetes crassas undulantes circulares concentricas in superficie agaris formans. Bases ascomatum nigrae, globosae sine decoribus. Colla ascomatum nigra sine hyphis ostiolaribus. Ascosporae reniformes non-septatae, hyalinae (5-)5.5-6(-6.5) $\times(1.5-) 1.5-2(-2) \mu \mathrm{m}$. Anamorpha Sporothrix conidiophoris hyalinis apicem versus ramosis. Conidia non-septata, hyalina oblonga vel cylindrica (5-)5.5-7(-8) $\times(2-) 2.5-3(-3.5) \mu \mathrm{m}$.

Colonies white to Buff (19"f) on MEA. Reverse Hazel (17"'b). Colony diameters reaching $16 \mathrm{~mm}$ in 10 days on MEA at $25^{\circ} \mathrm{C}$. Optimal growth at $25^{\circ} \mathrm{C}$. No growth at $5^{\circ} \mathrm{C}$ and at $35^{\circ} \mathrm{C}$. Mycelia forming thick, undulating, circular and concentric mats on agar surface. Ascomata produced by only a few strains, scattered over the colony surface and embedded within mycelium, producing white, creamy spore drops at the neck apices. Ascomatal necks black (68.5-)181.5-348(-378) $\mu \mathrm{m}$ long. Ascomatal bases black, globose (34.5-)66.5-135(-193.5) $\mu \mathrm{m}$ long and (35-)69-140.5(-206) $\mu \mathrm{m}$ wide, without ornamentations. Neck bases smooth. Ostiolar hyphae absent. Asci rarely seen, evanescent, deliquescing early in the development. Ascospores reniform, aseptate, hyaline (5-)5.5$6(-6.5) \times(1.5-) 1.5-2(-2) \mu \mathrm{m}$.

Anamorph: Sporothrix, conidiophores, hyaline, branched towards the apex, (9.5-)16-27(-34) $\times$ $(1.5-) 2-2.5(-3) \mu \mathrm{m}$. Conidia, aseptate, hyaline, oblong to cylindrical $(5-) 5.5-7(-8) \times(2-) 2.5-3(-$ 3.5) $\mu \mathrm{m}$.

Specimens examined: Australia, state of Queensland, isolated from wet E. grandis stems infested by Phoracantha beetles, August 2005, Michael J. Wingfield, holotype PREM60443, living culture CMW19396 = CBS127183. 


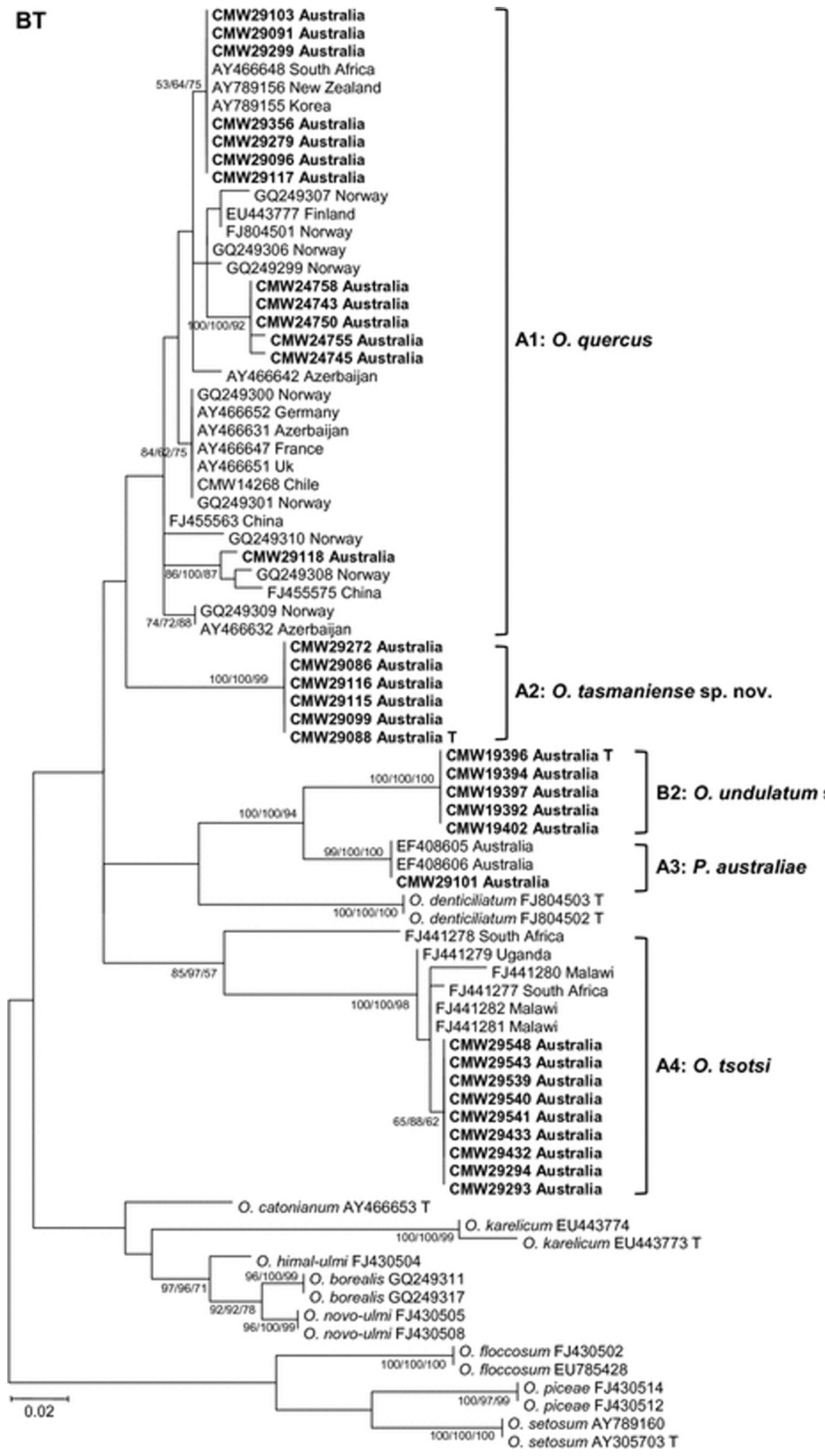


Figure 2. Phylogenetic tree produced from a maximum likelihood analysis of the $\beta$-tubulin gene (BT) sequence data, showing the relationship of Ophiostoma and Pesotum isolates from eucalypt trees in Australia with known species of Ophiostoma. Isolates sequenced in the study are in bold type font. Maximum-parsimony (MP) bootstrap values, Bayesian posterior probabilities and maximum-likelihood (ML) bootstrap values, respectively, are indicated at each relevant node. $\mathrm{T}=$ ex-type isolates.

Additional specimens examined: Australia, state of Queensland, isolated from E. grandis stems infested by Phoracantha beetles, August 2005, Michael J. Wingfield, paratype, living culture CMW19394 = PREM60438 = CBS127182, CMW19397 = PREM60437 = CBS127184.

Ophiostoma tasmaniense Kamgan-Nkuek, Jol. Roux \& Z.W. de Beer, sp. nov. (Fig. 5)

Etymology: The name refers to the state of Tasmania, Australia, where the fungus was first collected.

Coloniae in OMA fumeae, in MEA bubalinae in 10 diebus in $25^{\circ} \mathrm{C}$ ad $24 \mathrm{~mm}$ crescentes. Bases ascomatum nigrae, globosae cum pilis ostiolaribus. Colla ascomatum nigra cum hyphis ostiolaribus divergentibus. Ascosporae allantoideae non-septatae (4.5-)5-5.5(-6) $\mu \mathrm{m}$ longae $(1-) 1-1.5(-2) \mu \mathrm{m}$ latae. Anamorpha biformus. Gradus Pesotum conidiophoris erectis atrobrunneis apicem versus pallescentibus. Cellulae conidiogenae hyalinae acerosae. Conidia non-septata, hyalina (3.5-)4-4.5(5) $\mu \mathrm{m} \times(1-) 1-1.5(-2) \mu \mathrm{m}$. Gradi Sporothricis conidiophorae hyalinae cylindricae cum denticulis prominentibus. Conidia saepe septata, hyalina oblonga vel cylindrica interdum distincte pediformia $(8.5-) 11-19.5(-30.5) \times(2-) 2.5-4(-5) \mu \mathrm{m}$.

Colonies Smoke grey (21"'d) on OMA, with conidiophores forming light-coloured slimy heads, arranged in mostly circular rings or scattered over the colonies. On MEA colonies Buff (19'd), with conidiophores forming cream-coloured slimy heads scattered over the colonies, mostly surrounded by a mat of mycelia, reverse colonies Buff (19"d), becoming Honey (19"'b) towards the middle of the plates. Colony diameters reaching $24 \mathrm{~mm}$ in 10 days on MEA at $25^{\circ} \mathrm{C}$. Optimal growth temperature $25^{\circ} \mathrm{C}$, no growth at $5^{\circ} \mathrm{C}$ or at $35^{\circ} \mathrm{C}$.

Teleomorph state produced on Eucalyptus chips after random crossing between strains after about 1 month. Ascomatal bases black, globose (66.5-)95.5-144(-171.5) $\mu \mathrm{m}$ long and (71-)98.5-159(197.5) $\mu \mathrm{m}$ wide, with hyphal hairs. Ascomatal necks black (101-)499.5-1105.5(-1274) $\mu \mathrm{m}$ long, neck bases smooth (29-)34.5-46(-53) $\mu \mathrm{m}$ wide, middle of necks (17.5-)19.5-25.5(-29.5) $\mu \mathrm{m}$ wide, tips of necks (10.5-)11.5-17.5(-22) $\mu \mathrm{m}$ wide. Ostiolar hyphae present, divergent (11.5-)15.520.5(-21.5) $\mu \mathrm{m}$ long. Asci evanescent. Ascospores alantoid in side view, aseptate (4.5-)5-5.5(-6) $\mu \mathrm{m}$ long and (1-)1-1.5(-2) $\mu \mathrm{m}$ wide. Ascospores accumulating in round, creamy spore drops.

Anamorph: Pesotum, conidiophores synnematal, erect, dark brown at the bases, becoming lighter towards the apex, (472-)553.5-708.5(-774.5) $\mu \mathrm{m}$ long, (46.5-)67.5-110.5(-170) $\mu \mathrm{m}$ wide in the middle, (46-)54-90(-129.5) $\mu \mathrm{m}$ wide at the base. Conidiophore heads $(160-) 198-328(-452) \mu \mathrm{m}$ across the widest part, light brown, becoming hyaline towards the apex. Conidiogenous cells, hyaline, acerose (11.5-) 14.5-28.5(-41.5) $\mu \mathrm{m}$ long, $(1-) 1-1.5(-2) \mu \mathrm{m}$ wide, tapering towards the apex. Conidia produced through holoblastic, annellidic development. Conidia aseptate, hyaline, oblong to obovoid, accumulating in slimy heads on the apices of the synnemata, (3.5-)4-4.5(-5) $\mu \mathrm{m} \times(1-) 1-1.5(-2) \mu \mathrm{m}$.

Anamorph: Sporothrix, conidiophores, hyaline, cylindrical and branched, tapering towards the apex, $(10.5-) 27-61.5(-108.5) \times(1.5-) 2-2.5(-3) \mu \mathrm{m}$, prominent denticles present. Conidia, often septate, hyaline, oblong to cylindrical $(8.5-) 11-19.5(-30.5) \times(2-) 2.5-4(-5) \mu \mathrm{m}$ in size. 


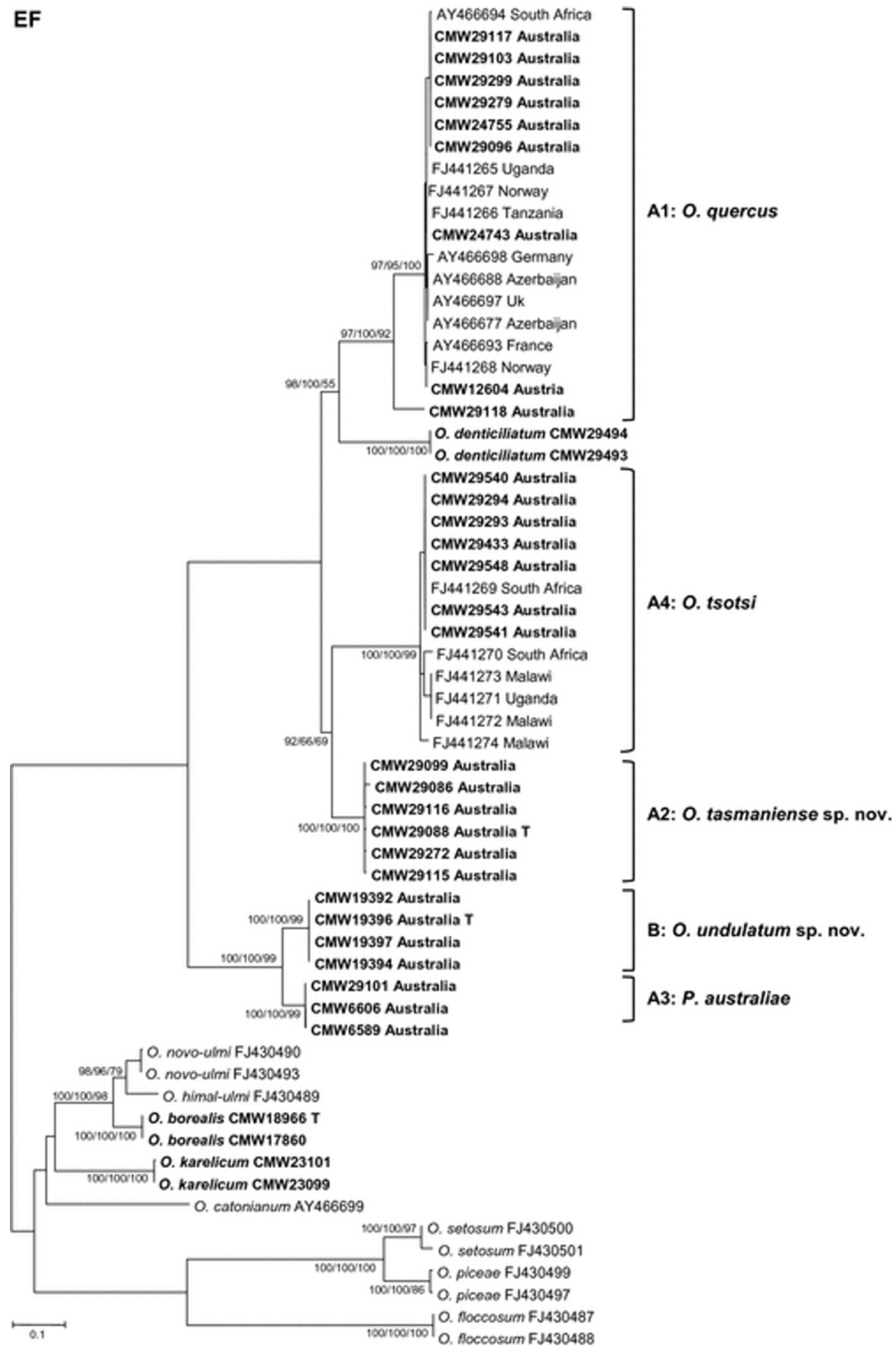


Figure 3. Phylogenetic tree produced from a maximum likelihood analysis of the transcription elongation factor-1 $\alpha$ gene (TEF) sequence data, showing the relationship between Ophiostoma and Pesotum isolates from eucalypt trees in Australia with known species of Ophiostoma. Isolates sequenced in the study are in bold type font. Maximum-parsimony (MP) bootstrap values, Bayesian posterior probabilities and maximum-likelihood (ML) bootstrap values, respectively, are indicated at each relevant node. $\mathrm{T}=$ ex-type isolates.

Specimens examined: Australia, state of Tasmania, Tarraleah State forest, isolated from cut stumps of Eucalyptus nitens, August 2008, G. Kamgan Nkuekam, holotype PREM60439, living culture CMW29088 = CBS127212.

Additional specimens examined: Australia, state of Tasmania, Burnie, isolated from E. globulus stumps. August 2008, G. Kamgan Nkuekam, paratype, living cultures CMW29115 = PREM60440 $=\mathrm{CBS} 127213, \mathrm{CMW} 29116=$ PREM60444 $=$ CBS127214.

\section{Distribution and host range of Ophiostoma spp.}

Five Ophiostoma species were identified from areas sampled in three different states of Australia. In NSW, two Ophiostoma spp. were identified. These comprised O. quercus, collected from four eucalypt tree species (E. grandis, E. dunnii, E. agglomerata and $C$. variegata) and $O$. tsotsi that was found on two Eucalyptus spp. (E. pilularis and E. grandis). In Tasmania, three Ophiostoma spp. were collected, including O. quercus from two Eucalyptus spp. (E. nitens and E. globulus), O. tasmaniense collected from three Eucalyptus spp. (E. globulus, E. nitens and E. saligna), and $P$. australiae collected from E. nitens. In Queensland, only $O$. undulatum was found on E. grandis trees.

\section{Pathogenicity tests}

Six weeks after inoculation, Eucalyptus trees were assessed for lesion development seen on the bark or at the cambial surface. All four fungal species used for inoculation, O. quercus, O. tsotsi, O. tasmaniense sp. nov. and $O$. undulatum sp. nov., produced very small lesions on both the bark and the xylem of inoculated E. grandis trees. Because no lesions could be measured for many inoculations, lesion lengths were analysed using GENMOD with a POISSON distribution and a link function of $\log$. Significant $(\mathrm{P}<0.0001)$ differences in lesion lengths on either the bark or the xylem were, however, not found between the four fungal species and their replicates when compared with each other (Figs 6,7). At the time when lesion lengths were recorded, trees were healthy with no signs of disease. All species other than $O$. undulatum were successfully isolated from the lesions. Control inoculations were covered with callus when the experiment was terminated and none of the test fungi was isolated from them.

\section{Discussion}

In the present study, five Ophiostoma spp. were identified from a survey of wounds on eucalypt trees in Australia. Two of these fungi were previously undescribed species for which the names $O$. undulatum and $O$. tasmaniense have been provided. $O$. tsotsi and $O$. quercus are reported for the first time from Eucalyptus trees in Australia, and the host and geographic ranges of $P$. australiae are expanded to include Eucalyptus nitens in Tasmania. The four species (O. quercus, O. tsotsi, O. tasmaniense sp. nov. and $O$. undulatum sp. nov.) inoculated onto E. grandis trees caused very small lesions, suggesting that they are not pathogens. 


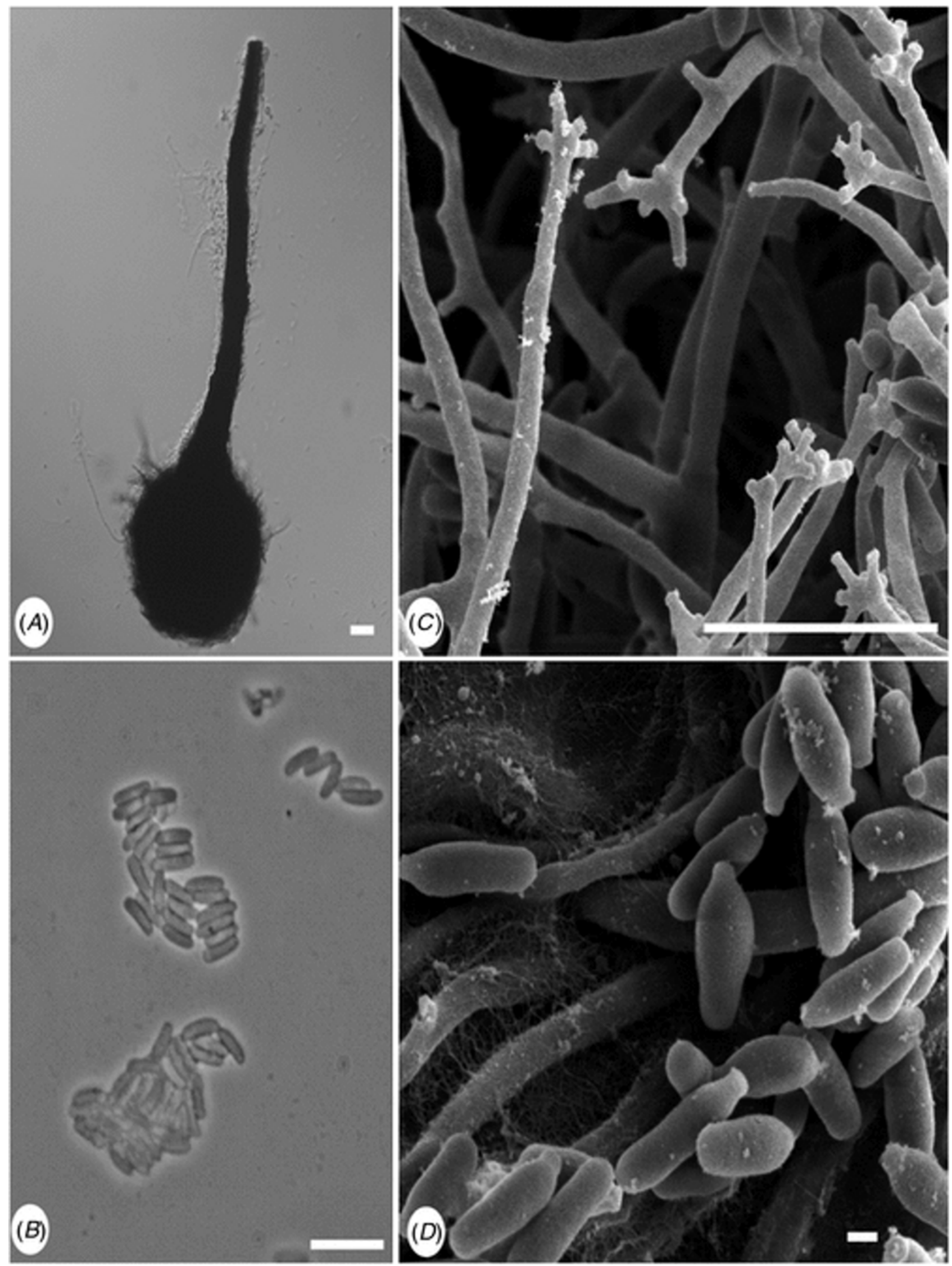

Figure 4. Morphological characteristics of Ophiostoma undulatum sp. nov. (A) Globose ascomatal base and a relatively short neck (scale bar $=20 \mu \mathrm{m})$, $(\mathrm{B})$ reniform ascospores (scale bar $=10 \mu \mathrm{m}$ ), (C) conidiogenous cells with denticles (scale bar $=10 \mu \mathrm{m}$ ) and (D) conidia, oblong to cylindrical, acerose (scale bar $=1 \mu \mathrm{m})$. 

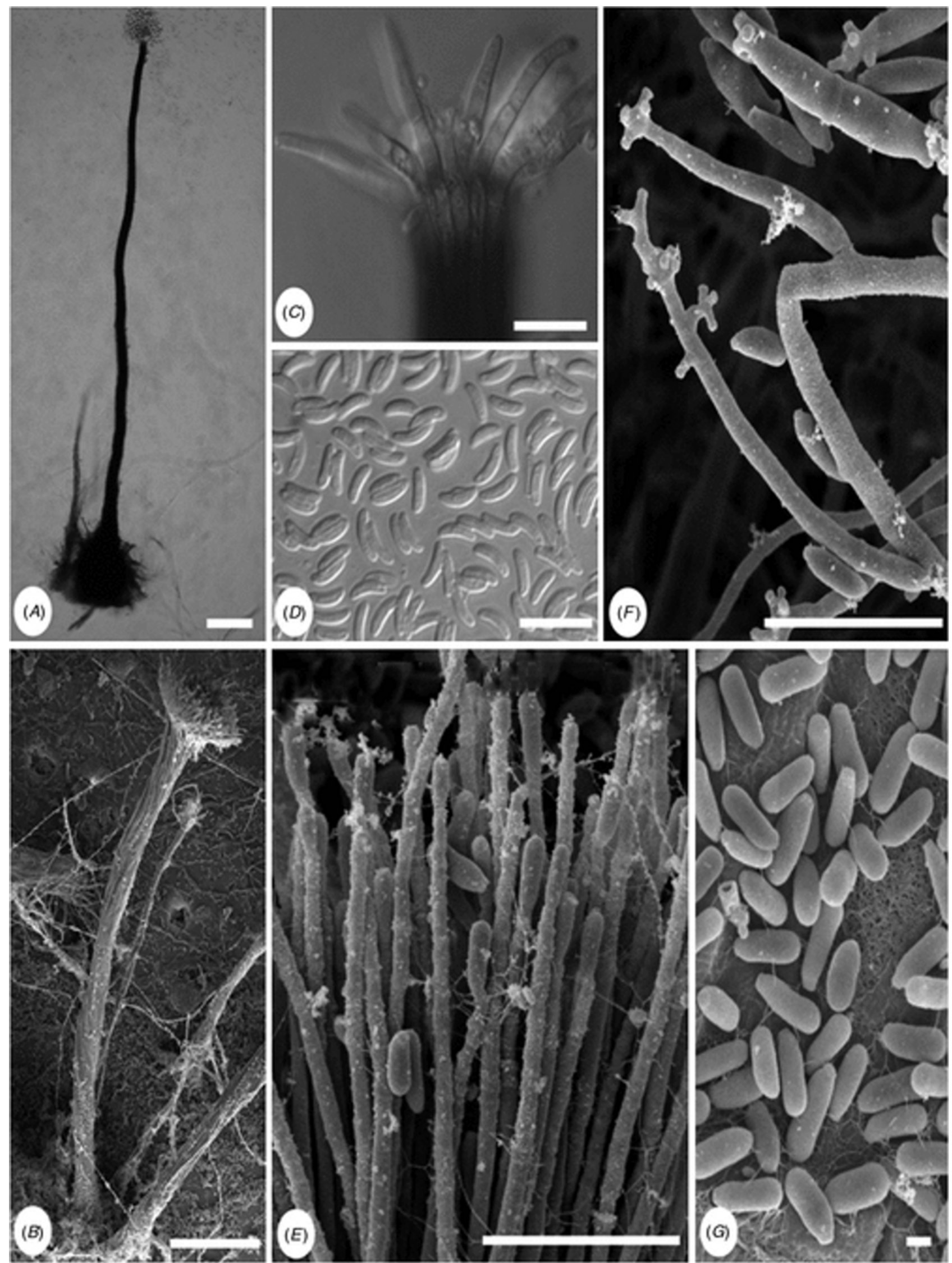

Figure 5. Morphological characteristics of Ophiostoma tasmaniense sp. nov. (A) Globose ascomatal base (scale bar $=100 \mu \mathrm{m}),(\mathrm{B})$ synnematal anamorph (scale bar $=100 \mu \mathrm{m}),(\mathrm{C})$ divergent ostiolar hyphae (scale bar $=10 \mu \mathrm{m}$ ), (D) allantoid ascospores (scale bar $=10 \mu \mathrm{m}$ ), (E) conidiogenous cell with annelidic proliferation of conidia (scale bar $=10 \mu \mathrm{m}$ ), (F) Sporothrix conidiogenous cells with denticles and mycelial conidia (scale bar $=10 \mu \mathrm{m}$ ) and $(\mathrm{G})$ oblong to cylindrical conidia (scale bar $=1 \mu \mathrm{m}$ ). 


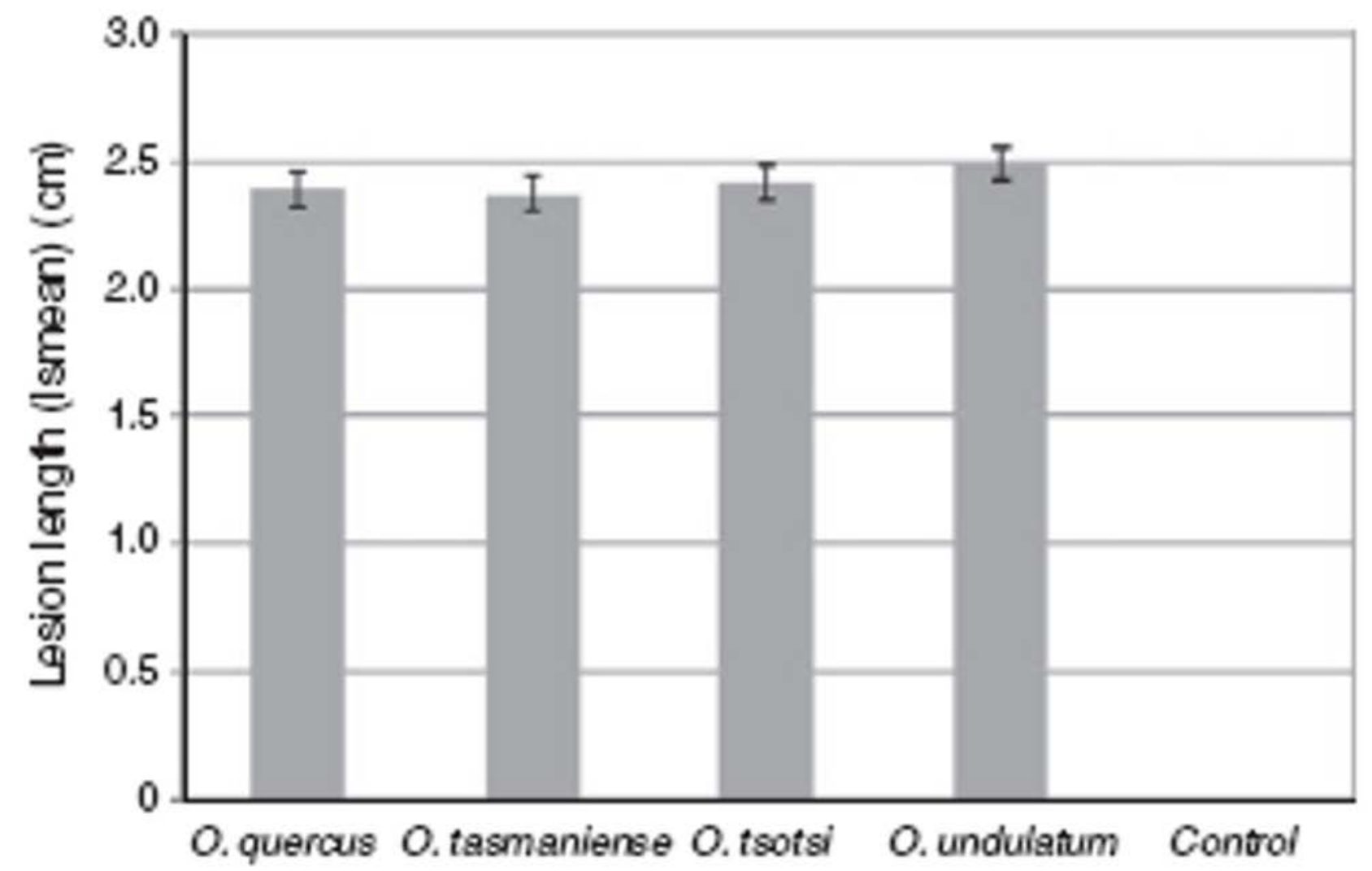

Figure 6. Histogram showing results of inoculation trial (bark lesion) with Ophiostoma quercus $($ Lsmean $=2.3937)$, O. tasmaniense $($ Lsmean $=2.3749)$, O. tsotsi $($ Lsmean $=2.4216)$, O. undulatum $($ Lsmean $=2.4920)$ on Eucalyptus grandis trees. Lsmean was determined for two isolates used per species, as indicated in Table $1(\mathrm{P}<0.0001$, confidence limit $=95 \%)$.

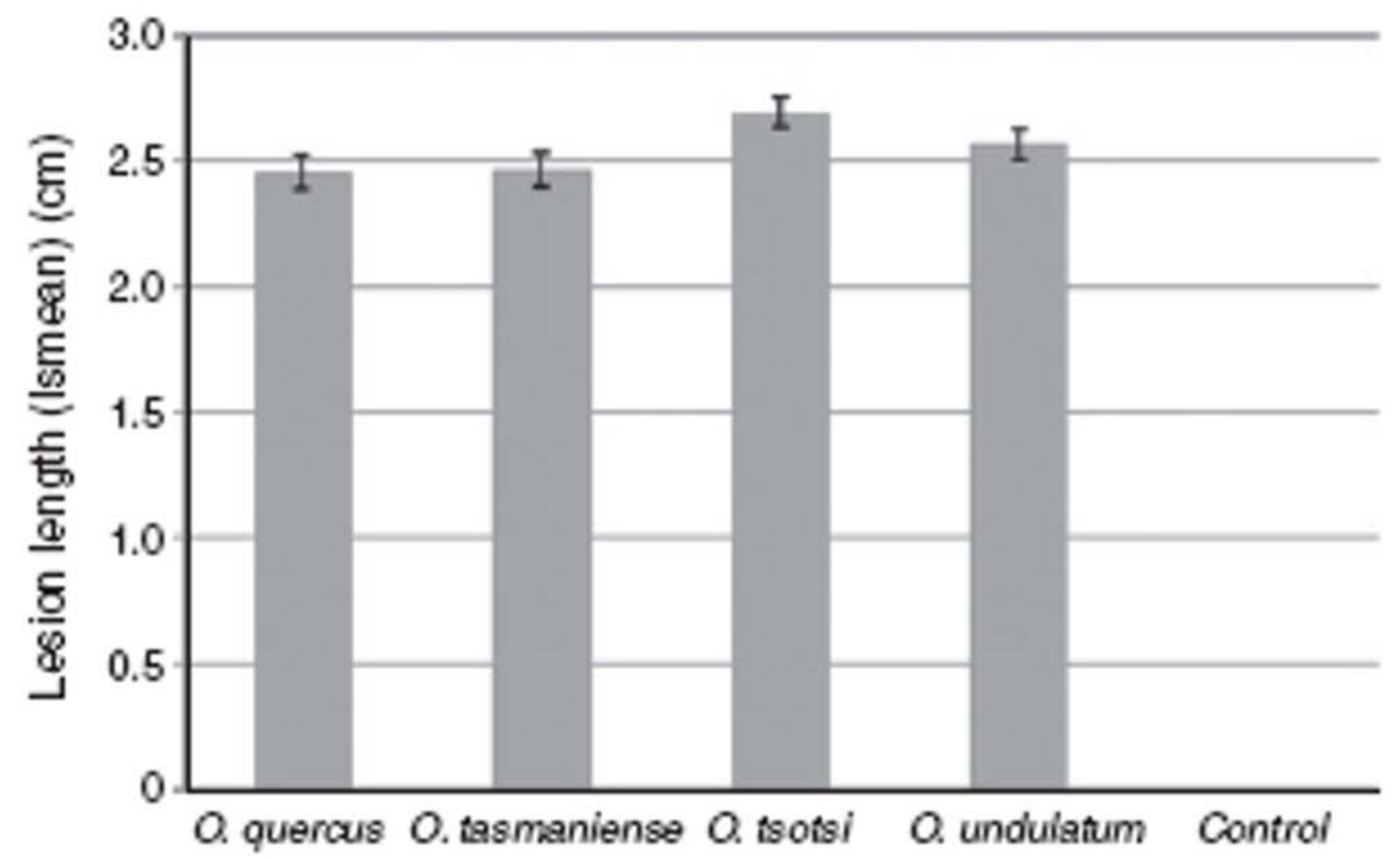

Figure 7. Histogram showing results of inoculation trial (xylem lesion) with Ophiostoma quercus $($ Lsmean $=2.4582), O$. tasmaniense $($ Lsmean $=2.4676), O$. tsotsi $($ Lsmean $=2.6975)$ and $O$. undulatum (Lsmean $=2.5726)$ on Eucalyptus grandis trees. Lsmean was determined for two 
isolates used per species, as indicated in Table $1(\mathrm{P}<0.0001$, confidence limit $=95 \%)$.

All five species identified in the study fall within a group of fungi commonly known as the $O$. piceae complex. This complex was first recognised to include nine morphologically similar species (Harrington et al. 2001), and has been the subject of considerable taxonomic confusion (Przybyl and de Hoog 1989; Harrington et al. 2001). O. tasmaniense, one of the new taxa described in the study, along with $O$. tsotsi, $O$. quercus and $P$. australiae, could not be differentiated in phylogenetic analyses by using only the ITS gene regions. This is not surprising as ITS gene regions have previously been shown to be insufficient to differentiate closely related members of the $O$. piceae complex (Chung et al. 2006; Kamgan Nkuekam et al. 2008a, 2010); thus, sequences for the BT gene region (Chung et al. 2006; Kamgan Nkuekam et al. 2008a, 2010) and, more recently the TEF gene region (Grobbelaar et al. 2009a)have been useful in distinguishing these species. On the basis of BT and TEF sequence data, $O$. tasmaniense described in the present study is most closely related to $O$. quercus. This expands the host and geographic ranges of members of the $O$. piceae complex in the southern hemisphere.

It was not surprising to find $P$. australiae infecting wounds of Eucalyptus trees in Australia. This fungus was recently described from wounds on native Acacia mearnsii trees near Cann River, Victoria, Australia (Kamgan Nkuekam et al. 2008a). Its teleomorph has not been seen and it could not be induced in the present study by crossing it with different strains isolated from $A$. mearnsii and Eucalyptus trees. Isolation of this fungus from Tasmania, and from Eucalyptus spp., expands its host and geographic range. It provides further evidence that it is native to the continent, because surveys for ophiostomatoid fungi on both A. mearnsii and Eucalyptus spp., for example in Africa, have not yielded this fungus.

Ophiostoma tsotsi, another species collected in the present study, was for many years confused with O. quercus. Recent studies have, however, considered cryptic species in the O. quercus complex, using polymorphic sequence repeats (Grobbelaar et al. 2009b) and multigene DNA-sequence phylogenies (Grobbelaar et al. 2009a) of isolates morphologically resembling O. quercus, originating from various hardwood trees in Africa. These data revealed a unique clade among these isolates, resulting in the description of $O$. tsotsi (Grobbelaar et al. 2010). Ophiostoma tsotsi is known only from hardwood tree species, including Eucalyptus and Acacia mearnsii in southern Africa and China (Grobbelaar et al. 2010, 2011). Its discovery on Eucalyptus trees in Australia expands its geographic range. The discovery also supports the view (Grobbelaar et al. 2010, 2011) that its distribution is probably more extensive than is currently known. The origin of the species remains unknown and more extensive sampling and population-genetic tools will be necessary to determine this.

Ophiostoma quercus has previously been reported from $P$. radiata in Australia (Harrington et al. 2001) and is known to occur on Eucalyptus spp. in Africa (De Beer et al. 2003). However, the present study is the first to report the fungus on eucalypt species in Australia. Ophiostoma quercus has a cosmopolitan distribution and a wide host range including hardwood and softwood trees and has been reported from numerous countries worldwide. The taxonomy of this fungus is, however, not fully resolved. It is suspected that there are cryptic species within what is now referred to as the $O$. quercus complex, based on the wide host and geographic ranges of isolates in this group. This is supported by the occurrence of subclades within the larger $O$. quercus clade in phylogenetic trees by using part of the ITS, BT (Kamgan Nkuekam et al. 2008a; Grobbelaar et al. 2009a; Linnakoski et al. 2009; Kamgan Nkuekam et al. 2010) and histone gene regions (Grobbelaar et al. 2009a). Isolates from Australia grouped in several different subclades of what is currently treated as the $O$. quercus complex (Kamgan Nkuekam et al. 2008a, 2010; Grobbelaar et al. 2009a; Linnakoski et al. 2009) that clearly deserves further taxonomic study. 
Ophiostoma tasmaniense is morphologically most similar to O. quercus. The two fungi produce only a Pesotum anamorph and a mycelial synanamorph (Sporothrix) in culture. The teleomorph state of $O$. tasmaniense was generated in the present study by crossing different strains of the fungus in different combinations on agar plates supplemented with Eucalyptus chips, as was the case for O. quercus (Morelet 1992; De Beer et al. 2003). It is clearly heterothallic and mating tester strains for it were produced in the present study. On the basis of morphology, O. tasmaniense differs from $O$. quercus in having substantially shorter ascomatal necks, and the synnematal conidia of $O$. tasmaniense emerged from conidiogenous cells that are much more clearly annellidic than those of O. quercus, which have a deceptive appearance of developing sympodially (Wingfield et al. 1991).

The newly described $O$. undulatum is phylogenetically most closely related to $P$. australiae. Unlike other members of the $O$. piceae complex, $O$. undulatum does not have a Pesotum anamorph, which is one of the morphological characters that was used to define the $O$. piceae complex (Harrington et al. 2001). Ophiostoma undulatum, although phylogenetically most closely related to $P$. australiae, does not share any morphological similarities with it. The new species produces thick and undulating mycelial mats, with ascomata embedded below the mycelium on both MEA and OMA.Furthermore, the anamorph state is a Sporothrix, in contrast to P. australiae, which has only a Pesotum anamorph (Kamgan Nkuekam et al. 2008a). Small differences were found in the growth rates of $O$. undulatum and $\mathrm{P}$. australiae at optimum temperatures. Colonies of $O$. undulatum reached $16 \mathrm{~mm}$ in 10 days at $25^{\circ} \mathrm{C}$, whereas in previous studies those of $P$. australiae reached $14 \mathrm{~mm}$ at the same temperature (Kamgan Nkuekam et al. 2008a). However, O. undulatum could grow at $30^{\circ} \mathrm{C}$, with colonies reaching $11 \mathrm{~mm}$ in 10 days, whereas $P$. australiae does not grow at $30^{\circ} \mathrm{C}$ or higher temperatures (Kamgan Nkuekam et al. 2008a).

The present study represents the most comprehensive consideration of fungi in the Ophiostomatales occurring on Eucalyptus and Corymbia trees in Australia. The results show that Ophiostoma spp. are more diverse on wounds on Eucalyptus trees in Australia than previously understood. Of the fungi collected in the present study, O. quercus and $O$. tsotsi have been reported from trees in countries other than Australia. This suggests intercontinental movement of these fungi, most likely through infected wood. The present study should provide a foundation for future studies considering trends in biodiversity, origin and pathogenicity of Ophiostoma in Australia and other countries.

\section{Acknowledgements}

We thank the DST/NRF Center of Excellence in Tree Health Biotechnology (CTHB), National Research Foundation of South Africa (NRF), the THRIP Initiative of the Department of Trade and Industry (THRIP/DST), members of the Tree Protection Co-operative Program (TPCP) and the University of Pretoria for funding and the facilities to undertake this study. We are also most grateful to the CSIRO Ecosystem Sciences (Tasmania), Industry \& Investment NSW in West Pennant Hills and the Queensland Department of Primary Industry and Fisheries in Brisbane for hosting G. Kamgan Nkuekam and providing him the opportunity to collect specimens in Australia. Forests NSW are thanked for assistance in locating sites in NSW. Professor Goeneveld and Dr Van der Linde from the Department of Statistics and Mr Alan Hall of the Electron Microscopy Unit, University of Pretoria, are thanked for their assistance with the statistical analyses and scanning electron microscopy, respectively. We further thank Dr Hugh Glen who provided the Latin diagnoses and made suggestions for the names of the new taxa.

\section{References}

Anonymous (2009) ‘Australia’s forests at a glance.' (Bureau of Rural Science: Canberra) 
Bridges JR, Moser JC (1986) Relationship of phoretic mites (Acari: Tarsonemidae) to the bluestaining fungus, Ceratocystis minor, in tree infested by southern pine beetle (Coleoptera: Scolytidae). Environmental Entomology, 15, 951-953

Chung W-H, Kim J, Yamaoka Y, Uzunovic A, Masuya H, Breuil C (2006) Ophiostoma breviusculum sp. nov. (Ophiostomatales, Ascomycota) is a new species in the Ophiostoma piceae complex associated with bark beetles in infesting larch in Japan. Mycologia, 98, 801-814

Conias S, Wilson P (1998) Epidemic cutaneous sporotrichosis: report of 16 cases in Queensland due to mouldy hay. The Australasian Journal of Dermatology, 39, 34-37

Crane JL, Schoknecht JD (1973) Conidiogenesis in Ceratocystis ulmi, Ceratocystis piceae and Graphium penicillioides. American Journal of Botany, 60, 346-354

De Beer ZW, Wingfield BD, Wingfield MJ (2003) The Ophiostoma piceae complex in the southern hemisphere: a phylogenetic study. Mycological Research, 107, 469-476

Glass NL, Donaldson GC (1995) Development of primer sets designed for use with the PCR to amplify conserved genes from filamentous Ascomycetes. Applied and Environmental Microbiology, 61, 1323-1330

Grobbelaar JW, Aghayeva D, De Beer ZW, Bloomer P, Wingfield MJ, Wingfield BD (2009a) Delimitation of Ophiostoma quercus and its synonyms using multiple gene phylogenies. Mycological Progress, 8, 221-236

Grobbelaar JW, Barnes I, Cortinas M-N, Bloomer P, Wingfield MJ, Wingfield BD (2009b) Development and characterization of polymorphic markers for the sap-stain fungus Ophiostoma quercus. Molecular Ecology Resources, 9, 399-401

Grobbelaar JW, De Beer ZW, Bloomer P, Wingfield MJ, Wingfield BD (2010) Ophiostoma tsotsi sp. nov., a wound-infesting fungus of hardwood trees in Africa. Mycopathologia, 169, 413-423

Grobbelaar JW, De Beer ZW, Bloomer P, Wingfield MJ, Zhou XD, Wingfield BD (2011) Discovery of Ophiostoma tsotsi on Eucalyptus wood chips in China. Mycoscience, 52, 111-118

Guindon S, Gascuel O (2003) A simple, fast, and accurate algorithm to estimate large phylogenies by maximum likelihood. Systematic Biology, 52, 696-704

Harrington TC, McNew D, Steimel J, Hofstra D, Farrell R (2001) Phylogeny and taxonomy of the Ophiostoma piceae complex and the Dutch elm disease fungi. Mycologia, 93, 111-136

Hill KD, Johnson LAS (1995) Systematic studies in the eucalypts 7. A revision of the bloodwoods, genus Corymbia (Myrtaceae). Tolepea, 6, 185-504

Iglesias-Trabado G, Wilstermann D (2008) Eucalyptus universalis. Global cultivated eucalypt forests map 2008. Version 1.0.1. In 'GIT Forestry Consulting's EUCALYPTOLOGICS'. Available at www.git-forestry.com [accessed March 2011].

Jacobs K, Wingfield MJ (2001) 'Leptographium species. Tree pathogens, insect associates and agents of blue stain.' (American Phytopathological Society Press: St Paul, MN) 
Jacobs K, Wingfield MJ, Wingfield BD, Yamaoka Y (1998) Comparison of Ophiostoma huntii and O. europhioides and description of O. aenigmaticum sp. nov. Mycological Research, 102, 289-294

Jacobs K, Bergdahl DR, Wingfield MJ, Halik S, Seifert KA, Bright DE, Wingfield BD (2004) Leptographium wingfieldii introduced into North America and found associated with exotic Tomicus piniperda and native bark beetles. Mycological Research, 108, 411-418

Kamgan Nkuekam G, Jacobs K, de Beer ZW, Wingfield MJ, Roux J (2008a) Pesotum australi sp. nov. and Ophiostoma quercus associated with Acacia mearnsii trees in Australia and Uganda. Australasian Plant Pathology, 37, 406-416

Kamgan Nkuekam G, Jacobs K, De Beer ZW, Wingfield MJ, Roux J (2008b) Ceratocystis and Ophiostoma species, including three new taxa, associated with wounds on native South African trees. Fungal Diversity, 29, 37-59

Kamgan Nkuekam G, Solheim H, De Beer ZW, Jacobs K, Grobbelaar JW, Wingfield MJ, Roux J (2010) Ophiostoma species, including Ophiostoma borealis sp. nov., infecting wounds of native broad-leaved trees in Norway. Cryptogamie. Mycologie, 31, 285-303

Katoh K, Misawa K, Kuma KI, Miyata T (2002) MAFFT: a novel method for rapid sequence alignment based on fast Fourier transform. Nucleic Acids Research, 30, 3059-3066

Kirisits T (2004) Fungal associates of European bark beetles with special emphasis on the ophiostomatoid fungi. In 'Bark and wood boring insects in living trees in Europe, a synthesis'. (Eds F Lieutier, KR Day, A Battistis, JC Gregoire, HF Evans) pp. 181-235. (Kluwer Academic Press: Dordrecht, The Netherlands)

Levieux J, Lieutier F, Moser JC, Perry TJ (1989) Transportation of phytopathogenic fungi by the bark beetle Ips sexdentatus Boemer and associated mites. Zeitschrift für Angewandte Entomologie, 108, $1-11$

Linnakoski R, De Beer ZW, Rousi M, Solheim H, Wingfield MJ (2009) Ophiostoma denticiliatum sp. nov. and other Ophiostoma species associated with the birch bark beetle in southern Norway. Persoonia, 23, 9-15

Malloch D, Blackwell M (1993) Dispersal biology of the ophiostomatoid fungi. In 'Ceratocystis and Ophiostoma: taxonomy, ecology, and pathogenicity'. (Eds MJ Wingfield, KA Seifert, JF Webber) pp. 195-206. (American Phytopathological Society Press: St Paul, MN)

Mathiesen-Käärik A (1953) Eine Ubersicht Uber die gewohnlichsten mit Borkenkafern assoziierten Blauepilze in Schweden und einige fur Schweden neue Blauepilze. Meddelanden fran Statens Skogsforskningsinstitutut, 43, 1-74

Morelet M (1992) Ophiostoma querci sur chene en France. Annales de la Societe des Sciences Naturelles et d'Archeologie de Toulon, 44, 106-112

Moser JC (1997) Phoretic mites and their hyperphoretic fungi associated with flying Ips typographus, Japonicus Niijima (Col., Scolytidae) in Japan. Journal of Applied Entomology, 121, 425-428 
O’Donnell K, Cigelnik E (1997) Two divergent intragenomic rDNA ITS2 types within a monophyletic lineage of the fungus Fusarium are nonorthologous. Molecular Phylogenetics and Evolution, 7, 103-116

O'Reilly LC, Altman SA (2006) Macrorestriction analysis of clinical and environmental isolates of Sporothrix schenckii. Journal of Clinical Microbiology, 44, 2547-2552

Paine TD, Raffa KF, Harrington TC (1997) Interactions among Scolytid bark beetles, their associated fungi, and live host conifers. Annual Review of Entomology, 42, 179-206

Posada D, Crandall KA (1998) MODELTEST: testing the model of DNA substitution. Bioinformatics, 14, 817-818

Potts BM, Pederick LA (2000) Morphology, phylogeny, origin, distribution and generic diversity of the eucalypts. In 'Diseases and pathogens of eucalypts'. (Eds PJ Keane, GA Kile, FD Podger, BN Brown) pp. 11-34. (CSIRO Publishing: Melbourne)

Przybyl K, de Hoog GS (1989) On the variability of Ophiostoma piceae. Antonie Van Leeuwenhoek, 55, 177-188

Rayner RW (1970) 'A mycological colour chart.' (Commonwealth Mycological Institute and British Mycological Society, Kew: London)

Ronquist F, Heuelsenbeck JP (2003) MrBayes: Bayesian phylogenetic inference under mixed models. Bioinformatics, 19, 1572-1574

Seifert KA (1993) Sapstain of commercial lumber by species of Ophiostoma and Ceratocystis. In 'Ceratocystis and Ophiostoma: taxonomy, ecology, and pathogenicity'. (Eds MJ Wingfield, KA Seifert, JF Webber) pp. 141-151. (American Phytopathological Society Press: St Paul, MN)

Sinclair WA, Lyon HH (2005) 'Diseases of trees and shrubs.' 2nd edn. (Cornell University Press: Ithaca, NY)

Stone C, Simpson JA (1987) Influence of Ips grandicollis on the incidence and spread of bluestain fungi in Pinus elliottii billets in north-eastern New South Wales. Australian Forestry, 50, 86-94

Stone C, Simpson JA (1989) Species associations in Ips grandicollis galleries in Pinus taeda. New Zealand Journal of Forestry Science, 20, 75-96

Stone C, Simpson JA (1991) Effect of six chemicals on the insects, mites, nematodes and fungi associated with Ips grandicollis (Eichhoff) (Coleoptera: Scolytidae) in north-eastern New South Wales. Journal of the Australian Entomological Society, 30, 21-28

Tamura K, Dudley J, Nei M, Kumar S (2007) MEGA4: molecular evolutionary genetics analysis (MEGA) software version 4.0. Molecular Biology and Evolution, 24, 1596-1599

Upadhyay HP (1981) 'A monograph of the genus Ceratocystis and Ceratocystiopsis.' (University of Georgia Press: Athens, GA)

Vaartaja O (1967) The common fungal associates of the bark beetle Ips grandicollis in Pinus radiata in South Australia. Australian Forest Research, 2, 40-43 
Whitney HS (1982) Relationships between bark beetles and symbiotic organism. In 'Bark beetles in North American conifers. A system for the study of evolutionary biology'. (Eds JB Mitton, KB Sturgeon) pp. 183-211. (University of Texas Press: Austin, TX)

White TJ, Bruns T, Lee S, Taylor J (1990) Amplification and direct sequencing of fungal ribosomal RNA genes for phylogenetics. In 'PCR protocols: a sequencing guide to methods and applications'. (Eds MA Innis, DH Gelfand, JJ Sninsky, TJ White) pp. 315-322. (Academic Press: San Diego, CA)

Wingfield MJ, Kendrick B, Schalk Van Wyk SP (1991) Analysis of conidium ontogeny in anamorphs of Ophiostoma: Pesotum and Phialographium are synonyms of Graphium. Mycological Research, 95, 1328-1333

Wingfield MJ, Seifert KA, Webber JF (1993) Ceratocystis and Ophiostoma: taxonomy, ecology and pathogenicity. (American Phytopathological Society Press: St Paul, MN)

Zipfel RD, De Beer ZW, Jacobs K, Wingfield MJ, Wingfield BD (2006) Multigene phylogenies define Ceratocystiopsis and Grosmannia distinct from Ophiostoma. Studies in Mycology, 55, 75-97 